\title{
Knowledge and Practices of Wound Care Among Animal Bite Cases Attended at Institute of Public Health.
}

\author{
Ara $\mathrm{R}^{1}$, Uddin $\mathrm{MN}^{2}$, Wahab MA ${ }^{3}$, Ferdousi $\mathrm{S}^{4}$, Khondker L ${ }^{5}$, Khan MSI
}

\begin{abstract}
Animal bite is common in Bangladesh. A cross sectional type of descriptive study was carried out at the Institute of Public Health (IPH), Dhaka to find out the knowledge and practices related to wound care among animal bite cases during the month of February, 1998. A total of 200 patients were interviewed, $55 \%$ of them came from urban area. Maximum (65.5\%) patients were teenagers and adult (above 13 yrs.) with mean age 22.15 yrs. Male and female ratio was 80.5:19.5. Majority of cases were poor (76.5\%) and only $12 \%$ attained educational level of SSC pass or above. In $92.5 \%$ cases dog was the biting animal, $60 \%$ of which were stray. Only 91(45.5\%) patients took immediate measures for wound care. Of them only 11 patients knew and washed the wound by soap and water and 3 patients did it after getting advice from physicians. 134 (67\%) patients consulted with physicians one hour to several days after, whereas 33\% within one hour. Among the attending physicians $31.5 \%$ were MBBS doctors but $57.5 \%$ were Kabiraz, Fakir, Moullana and others. In 50 present animal bite cases, Fold remedies or herbal medicine were advised in comparison to $42 \%$ for vaccination. But only $3(1.5 \%)$ patients got the message of wound care by washing with soap and water. Emphasis on planning on educational programme on "What people should do after an animal bite" has been recommended.
\end{abstract}

01. Dr. Rowshan Ara, MBBS, MPH, M. Phil Assistant Professor, Department of Community Medicine Dhaka Medical College, Dhaka

02. Major General (Dr). Md Nasir Uddin, MBBS, MPH, M. Phil Commandant, Armed Forces Medical College, Dhaka.

03. Lt Col (Retd) Dr. Md Abdul Wahab MBBS, DDV, MCPS, FCPS, FRCP, FACP Professor, Department of Dermatology and Venereology Bangabandhu Sheikh Mujib Medical University,Dhaka.

04. Dr. Shahneela Ferdousi, MBBS, M.Phil, M.D Assistant Professor, Department of Biochemistry Dhaka Medical College, Dhaka.

05. Corresponding Author:

Dr. Lubna Khondker, MBBS, MPH, DDV, MCPS, FCPS. Assistant Professor, Department of Public Health and Informatics Bangabandhu Sheikh Mujib Medical University, Dhaka

06. Lt. Col. (Dr). Md Shirajul Islam Khan, MBBS, DDV, MCPS. Graded Specialist in Dermatology and Venereology Combined Military Hospital Dhaka cantonment, Dhaka.

\section{Introduction}

Rabies or commonly known as "Hydrophobia" (Fear of water) is an important among the zoonotic diseases in Bangladesh. It is primarily a disease of warm blooded animals such as dog, cat, jackal, fox, mongoose, wolves etc. but transmitted to human being usually by the bites of rabid animals. The disease is characterized clinically by a long and variable incubation period, a short period of illness due to acute encephalitis, ending in death. It is the only communicable disease of man which can be regarded as $100 \%$ fatal $^{1}$. Rabies is one of the oldest diseases known to man and has a world wide distribution except British Isles, Scandinavia, Cyprus, Australia, New-Zealand, Taiwan² According to the FAO/WHO/OIE Animal Health yearbook(1), 87 countries and territories are still infected by rabies, these areas accounting for more than $99 \%$ of all reported human deaths for rabies is nearly 25,000 in a year and about 3 million people exposed to animal bites in every year'.

Rabies is a public health problem of considerable magnitude in Bangladesh but the actual prevalence is not known as there is no surveillance or study in this respect ${ }^{4}$. From the records of antirabies vaccine supply of Institute of Public Health (IPH), it is estimated that about 60,000 Persons undergo anti-rabies vaccine (ARV) treatment per year. Zia Uddin $^{5}$ reported that in Bangladesh about 2000 patients die from rabies in every year but he did not mention the exact source of his data. Only a few hydrophobic cases are recorded at the Infectious Disease Hospital but most of the cases remain unrecorded or unnotified. This may be due to the fact that the people of animal bite cases irrespective of economic status, led by superstitious belief and faith which turn them to fold remedies ${ }^{6}$.

Although rabies is a fatal disease still prevention is possible by local treatment of wound and anti rabies vaccination. Among local treatment of wound, as a first aid treatment wound care is very much important, others include chemical treatment, use of anti rabies serum, Tetanus Toxoid and antibiotics lastly care about suturing ${ }^{7}$. Immediate first aid procedures recommended are thorough flushing and washing of the wound with soap and water, detergent or other substances of proven lethal effect on rabies virus8 Local treatment of wound is of maximum value when applied immediately of virus at the inoculation site as much as possible before getting time to multiply and to penetrate the peripheral nerve. Immediate cleansing and flushing with soap and water of all wound, scratches adjoining area is a critically important step in the prevention of rabies. But 
unfortunately very few patients get it in right time. The animal bites cases come to IPH for collection of vaccine have to show prescription from registered MBBS doctor. So we can hope that the preliminary knowledge about wound care was given by them. But patients got only the massage of vaccination but not the message "how to take care wound'. The study was taken to generate information that could be useful in creating better health educational approaches among the community people for prevention of rabies.

\section{Materials and Methods}

This is a cross sectional type of descriptive study, conducted with patients of animal bite attended for receiving injection anti-rabies vaccine (ARV). Anti-rabies vaccine (ARV) section of Institute of Public Health (IPH), Mohakhali, Dhaka was the place of study. The reasons for selecting this place was, this is the only Govt' centre for production of Antirabies vaccine (ARV) and it supplies vaccine directly to the patients of animal bite or to their authorized person. IPH also supply vaccine throughout the country by govt. or non govt. health or other agencies. But the supply don't fulfil the present demand. So everyday many people from different places come for advice or collection of vaccine. It is therfore, felt that a good number of patients of all classes may be available here.

For this study, interview was conducted with the patients attended during the month of February, 1998 for collection of vaccine. In case of children (under 13 years) opinion was collected from the attending guardian. Systematic random sampling technique was applied. About 2000 to 2500 patients (From the records of vaccine supply section) get vaccine in every month from IPH. Among nearly about 600-700 patients directly come to receive ARV. Sample size calculated was around 234 and sampling interval was 2 . Interviewer administered questionnaire was used for data collection. The questionnaire was in Bengali for easy understanding of the patients and pretested. Interview was conducted on patients of animal bite cases or in case of children (under 13 years) with attending guardians. Before beginning of the interview, the nature of the study was explained to the patients and their verbal consents were taken. Some information's were collected from records. For analysis of data all the variables were taken into consideration. For simplification a master table was prepared manually. From master table individual tables on different variable were prepared and analyzed. Data were presented mostly in univariate and bivariate table.

\section{Results}

This cross sectional type of descriptive study conducted with patients of animal bite attended for receiving injection anti-rabies vaccine (ARV) in the Institute of Public Health, Mohakhali, Dhaka. The data collected from 200 animal bite cases were analyzed. Figure I showed Pie diagram showed the residence distribution of animal bite cases. More than half of the patients came from urban area (55\%) in comparison to rural area (45\%).

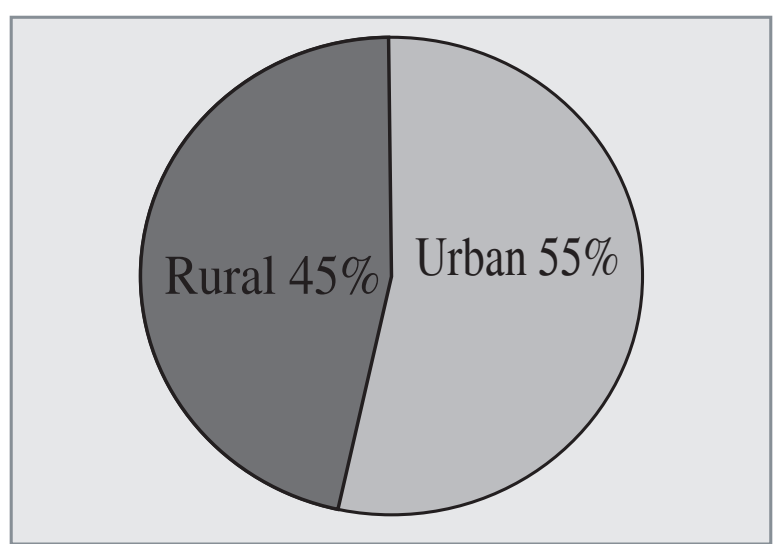

Figure I: Pie diagram showing distribution of residence.

Table-I showed the demographical characterastic of the study population. Among 200 patient 161 (80.4\%) were male \& $39(19.5 \%)$ were female. Maximum patients $(65.5 \%)$ were teenagers and adult (Age group 13yrs and above). Children below 13 yrs age group were $34.5 \%$. Mean age was 22.15 years. Sex distribution showed that males have 4 times more, risk of animal bite than females. The educational status among 200 patients 90 (45\%) never attended school. The next frequency was in primary level (who read upto class V) with $23 \%$ cases, then secondary level (who read VI to VIII) with $20 \%$ cases. H.S.C. pass and above included only $17(8.5 \%)$ cases. A smaller number 7 (3.5\%) patients passed S.S.C examination. The monthly family income, majority $(77.5 \%)$ were found poor having income taka 4000 or below per month. In remaining 45 $(22.5 \%)$ cases, the income was above Tk. $4000 \&$ more.

Table I: Demographical Character of Study Population.

\begin{tabular}{|c|c|c|}
\hline Variable & No. of cases & Percentage \\
\hline Sex ( Male: Female) & $161: 39$ & $80.5 / 19.5$ \\
\hline Educational Level: & & \\
No. schooling & 90 & 45.0 \\
Primary level & 46 & 23.0 \\
Secondary level & 40 & 20.0 \\
SSC pass & 7 & 3.5 \\
HSC pass \& above & 17 & 8.5 \\
\hline Income Level: Family & & \\
Incomein Taka per month & 155 & 77.5 \\
$<4000$ & 45 & 22.5 \\
> 4000 &
\end{tabular}

Tk. 4000 is taken to define poverty level.

Characteristics of biting animals showed in table II that in maximum cases dog was the biting animals (92.5\%) irrespective of pet or stray. About $60 \%$ dogs were stray.

Table II: Characteristics of biting animals identified

\begin{tabular}{|l|r|c|c|r|}
\hline Species & Pets (\%) & Stray (\%) & Wild (\%) & Total (Percent) \\
\hline Dog & $75(37.5)$ & $110(55.0)$ & 0 & $185(92.5)$ \\
Cat & $6(3.0)$ & - & - & $6(3.0)$ \\
Others & $6(3.0)$ & - & $3(1.5)$ & $9(4.5)$ \\
\hline Total & $87(43.5)$ & $110(55.0)$ & $3(1.5)$ & $200(100.0)$ \\
\hline
\end{tabular}


In Table III, the findings showed that only 91(45.5\%) patients took immediate measures for wound care and there is little difference in educated group (Primary level to H.S.C pass or above) in relation of taking immediate measures or not (59 \& 51 respectively).

Table III: Level of Education \& Immediate measure taken for wound care.

\begin{tabular}{|l|r|r|r|}
\hline \multirow{2}{*}{$\begin{array}{l}\text { Level of } \\
\text { Education }\end{array}$} & \multicolumn{2}{|c|}{$\begin{array}{r}\text { Immediate measures taken by } \\
\text { the patients }\end{array}$} & \multirow{2}{*}{$\begin{array}{c}\text { Total } \\
\text { (Percent) }\end{array}$} \\
\cline { 2 - 3 } & Yes/\% & No/\% & \\
\hline NO schooling & $32(16.0)$ & $58(29.0)$ & $90(45.0)$ \\
Primary level & $20(10.0)$ & $26(13.0)$ & $46(23.0)$ \\
Secondary level & $19(9.5)$ & $21(10.5)$ & $40(20.0)$ \\
SSC Pass & $7(3.5)$ & - & $7(3.5)$ \\
HSC pass \& Above & $13(6.5)$ & $4(2.0)$ & $17(8.5)$ \\
\hline Total & $91(45.5)$ & $109(54.5)$ & $200(100)$ \\
\hline
\end{tabular}

Table- IV: 91, patients took immediate measures either self initiated $66(72.53 \%)$ or after physician consultation 25(27.47\%). Among them only 14 patients took proper care of wound i.e washing with soap and water after animal bite and only 3 patients did it after getting advice from physicians. 28 patients washed or swabbed the wound with only water. Whereas in 31 cases antiseptics were used. Salt, hot iron, Leave juice or turmeric was applied locally for wound care in 18 cases.

Table IV: Measures taken by the patients for wound care.

\begin{tabular}{|c|c|c|c|}
\hline \multirow{2}{*}{ Wound care measures } & \multicolumn{2}{|c|}{ No. of Cases } & \multirow[b]{2}{*}{$\begin{array}{c}\text { Total } \\
\text { (Percent) }\end{array}$} \\
\hline & $\begin{array}{c}\text { Self initiated } \\
(\%)\end{array}$ & $\begin{array}{c}\text { Physician } \\
\text { Consulted (\%) }\end{array}$ & \\
\hline $\begin{array}{l}\text { Wash with soap } \\
\text { and water }\end{array}$ & $11(12.09)$ & $3(3.30)$ & $14(15.38)$ \\
\hline $\begin{array}{l}\text { Wash or swab with } \\
\text { only water }\end{array}$ & $28(30.77)$ & - & $28(30.77)$ \\
\hline $\begin{array}{l}\text { Application of } \\
\text { antiseptic } \\
\text { (Savlon or dettol) } \\
\end{array}$ & $17(18.68)$ & $14(15.38)$ & $31(34.07)$ \\
\hline $\begin{array}{l}\text { Application of others } \\
\text { (Salt, hot iron, leave, } \\
\text { juice, turmeric etc. }\end{array}$ & $10(10.99)$ & $8(8.79)$ & $18(19.78)$ \\
\hline Total & $66(72.53)$ & $25(27.47)$ & $91(100)$ \\
\hline
\end{tabular}

Table V: In relation of education, out of 14 those who took care of wound by soap and water 10 patients had educational background. Again 59 educated persons took immediate care in comparison to $32 \mathrm{n}$ on educated person.

Table V: Distribution of patients taking measures in relation of education level.

\begin{tabular}{|l|c|c|c|c|r|}
\hline \multirow{2}{*}{ Educational level } & \multicolumn{4}{|c|}{ Types of measure } & \multirow{2}{*}{$\begin{array}{c}\text { Total } \\
\text { (Percent) }\end{array}$} \\
\cline { 2 - 5 } & $\begin{array}{c}\text { Soap } \\
\text { nd water }\end{array}$ & $\begin{array}{c}\text { Only } \\
\text { water }\end{array}$ & Antiseptics & others & \\
\hline No schooling & 4 & 14 & 9 & 5 & $32(35.16)$ \\
Primary level & 3 & 7 & 5 & 5 & $20(21.98)$ \\
Secondary pass & 2 & 4 & 7 & 6 & $19(20.88)$ \\
SSC pass & 3 & 0 & 3 & 1 & $7(7.69)$ \\
HSC Pass and above & 2 & 3 & 7 & 1 & $13(14.29)$ \\
\hline Total & $14(15.38)$ & $28(30.77)$ & $31(34.07)$ & $18(19.78)$ & $91(100)$ \\
\hline
\end{tabular}

Table VI, VII showed the time gap between animal bite and physicians visit, different types of physician \& advice taken by the animal bite cases. $33 \%$ patients visited physicians within 1 hour and rest $67.0 \%$ met after one hour to several days (Table-VI). In types of physician (Table-VII) 57.5\% patient consulted first with Kabiraz, Moullana, Fakir \& others after an animal bite. $31.5 \%$ went to MBBS doctor \& rest $11 \%$ to pollychikitsok.

Table VI: Time gap between animal bite and physician consultation.

\begin{tabular}{|l|c|c|}
\hline Time gap in hour & No. of cases & percent \\
\hline $\begin{array}{l}\text { Within 1 hour } \\
\text { More than 1 hour }\end{array}$ & 66 & 33.0 \\
to several & 134 & 67.0 \\
days & & 100.0 \\
\hline Total & 200 & \\
\hline
\end{tabular}

Table VII: Distribution of the patients by type of physicians attended..

\begin{tabular}{|l|c|c|}
\hline Physicians & No. of cases attended & Percent \\
\hline MBBS & 63 & 31.5 \\
Pollychikitsok & 22 & 11.0 \\
Kabiraz & 57 & 28.5 \\
Moullana \& Fakir & 28 & 14.0 \\
Medicine seller & 10 & 5.0 \\
Others & 20 & 10.0 \\
(Close relatives, & & \\
neighbors) & & \\
\hline Total & 200 & 100.0 \\
\hline
\end{tabular}

The finding of table VIII, showed that $50 \%$ of total patient got Folk remedies, herbal or combination of those. Only 3 patients got the advice of washing of wound with soap and water. Antiseptics were applied and or advice of vaccination was given to $42 \%$ patients.

Table VIII: Advice taken by the animal bite cases

\begin{tabular}{|l|c|c|}
\hline Advices & No. of cases & percent \\
\hline $\begin{array}{l}\text { Folk medicine or } \\
\text { Herbal or combination }\end{array}$ & 100 & 50.0 \\
$\begin{array}{l}\text { Wash with soap \& water } \\
\text { Application of antiseptic } \\
\text { and or advice for vaccination }\end{array}$ & 3 & 1.5 \\
$\begin{array}{l}\text { Use other medicine } \\
\text { (Pain killer tab. Injection }\end{array}$ & 13 & 42.0 \\
Capsule etc.) & 200 & 6.5 \\
\hline Total & & 100.0 \\
\hline
\end{tabular}

\section{Discussion}

This is a cross sectional study, conducted with patients of animal bite attended for receiving injection ARV to find out knowledge and practices related to wound care among animal bite cases. ARV section of Institute of Public Health, Mohakhali, Dhaka was the place of study. With many limitations, 200 animal bite cases were interviewed during the month of February'98 at Institute of Public Health. Out 
of 200, 55\% came from urban area. This result may not reflects the real situation, because of exclusion of those who came for collection of antirabies vaccine without patients \& since the study place is situated in Dhaka it is not possible for all to come. Maximum number of animal bite cases were teenagers and adult and $80.5 \%$ were male. This observation is similar to the findings of Ali Wazed \& others ${ }^{9}$ and Rahman Mizanur \& others ${ }^{10}$ who conducted their study in Dhaka. Actually for all practical purposes males are more likely to come in contact with stray dogs \& as such they are more prone to be bitten. Majority of cases were poor (76.5\%) and only $12 \%$ attained education level S.S.C pass or above. Among the biting animals identified, $92.5 \%$ were dogs and $60 \%$ of them were stray, this finding is also similar to the studies of Ali Wazed ${ }^{9}$ and Rahman Mizanur ${ }^{10}$.

For the care of any bite wound, immediate vigorous washing \& flushing of the wound with copious amounts of water and soap is essential. But in this study, only $91(45.5 \%)$ patients were found who took care of wound either self initiated or after consultation with physicians. Among those, only 14 patients followed proper care of wound by washing with soap and water. In relation of education, 10 patients out of 14 have educational background. But no date or study was found for comparison. Irrespective of measures taken or not, $33 \%$ of the patients consulted with physicians within one hour and $67 \%$ patients after 1 hour of animal bite. Among the visited physicians kabiraz (28.5\%), Moullana \& Fakir (14\%), and pollychikitsok $(11.0 \%)$ constituted the major group whereas MBBS were $31.5 \%$. Half of the patients got folk remedies or herbal medicine or combination. This finding indicates that strong belief \& superstitions are prevailing among the animal bite cases which lead them to seek folk remedies. Raj Subba of India ${ }^{4} \&$ Islam $A^{6}$ also mentioned about this in their articles. In $42 \%$ cases wound was swabbed with antiseptic and or advice of Antirabies vaccine were given, whereas only $3(1.5 \%)$ patients got the advice of wound care by washing with soap and water.

All these findings indicate the importance of creating awareness about local treatment of wound among the health workers as well as general people of our country for better prevention of rabies. Because proper wound care and vaccination can save a life from fatal disease like rabies.

This study was a descriptive one, which try to find out knowledge and practices related to wound care among animal bite cases attended at IPH during the month of February'98. Among the major findings, it was found that out of 200 animal bite cases, one third cases were teenagers and adult. Males are four times more at risk of animal bite than female. Occupation, income and educational background suggested that they had come from poor families. In about half of the cases dog was the biting animal and more than half of the dogs were stray. Thus a large number of biting incidences and consequent risk of exposure to rabies may be prevented if adequate measures are taken to eliminate stray dogs. Only less than half patients took immediate measures. Only 11 of them used proper method i.e wound care by washing with soap and water and 3 patients did it after physician consultation.
The patients of animal bite cases led by superstitious belief and faith, supported by the fact that more than half cases consulted with kabiraz, moullana, fakir and other whereas one third cases with MBBS doctor after an incidence of animal bite. Half of the patient got the advice of Folk remendies or harbal medicine or combination in comparison less than half for vaccination. Only 3 patients (1.5\%) got the message of wound care by soap and water. Patients who were interviewed know about vaccination but still they don't know “what should do' after an animal bite. Emphasis was given on planning and implementation of health educational approaches among the community people for better prevention of Rabies.

\section{Recommendations}

In the light of the findings of this study certain recommendations are considered and givev below:

1. Orientation of health workers or primary health care workers on the local treatment of wound caused by animal bite.

2. Awareness should be created among the people on immunization of pet animals.

3. Programme should be taken for elimination of stray dogs. Planning and implementation of educational programme is essential on "What people should know" and "What people should do" when they become a victim of animal bite. Newspaper, Radio, Television, leaflets, Poster, film show can be used for communicating the message.

\section{Acknowledgement}

The authors are grateful to the Bangladesh Medical Research Council(BMRC), for their support by a financial grant.

\section{References}

1. Park J. E and Park K. Text book of Preventive and Social Medicine. 16th edition India:M/s Banarsidas Bhanot Publishers;1989;200-205.

2. Eds weatherll DJ. Oxford Text book of Medicine. 2nd Edition; 1987;1:5105-13.

3. Bulletin WHO 64;1986:883-887.

4. Raj Subba. Rabies. Journal of Madurai Medical College, India 1991;4:56-64.

5. Ahmad Ziauddin. Rabies- General Considerations, Prevention and Control, IPH, Dhaka 1986;2:43-52.

6. Islam A. Rabie and its economic Impact. National Workshop on control of Rabies 1995;2:23-29.

7. WHO Recommendations on Rabies: Post Exposure Treatment and the correct technique of intradermal immunization against Rabies WHO/EMC/Zoo.966.

8. WHO Technical Report. Serial No. 709:1984.

9. Ali W, Khan FK, Shariuddoulah, Majumder JU. Surveillance of Rabies in Dhaka. BMRC Bulletin 11, December, 1997:3:P117-123.

10. Rahman M, Ali A, Rab A, Rahman M. Rabies and animal bite patients al the infectious disease hospital, Dhaka. JOPSOM 1996;15:11-14. 